STUDI

FRANCESI

\section{Studi Francesi}

Rivista quadrimestrale fondata da Franco Simone

170 (LVII | II) | 2013

Varia

\title{
Per Buvik, L'Identité des contraires. Sur Georges \\ Bataille et le christianisme
}

\section{Michela Gardini}

\section{(2) OpenEdition \\ 1 Journals}

\section{Edizione digitale}

URL: https://journals.openedition.org/studifrancesi/3207

DOI: 10.4000/studifrancesi.3207

ISSN: 2421-5856

Editore

Rosenberg \& Sellier

\section{Edizione cartacea}

Data di pubblicazione: 1 juillet 2013

Paginazione: 486

ISSN: 0039-2944

\section{Notizia bibliografica digitale}

Michela Gardini, «Per Buvik, L'Identité des contraires. Sur Georges Bataille et le christianisme», Studi

Francesi [Online], 170 (LVII | II) | 2013, online dal 30 novembre 2015, consultato il 02 février 2023. URL: http://journals.openedition.org/studifrancesi/3207 ; DOI: https://doi.org/10.4000/studifrancesi.3207

Questo documento è stato generato automaticamente il 2 février 2023.

\section{(c) (i) () $\Theta$}

Creative Commons - Attribuzione - Non commerciale - Non opere derivate 4.0 Internazionale - CC BYNC-ND 4.0

https://creativecommons.org/licenses/by-nc-nd/4.0/ 


\title{
Per Buvik, L'Identité des contraires. Sur Georges Bataille et le christianisme
}

\author{
Michela Gardini
}

\section{NOTIZIA}

PER BUVIK, L'Identité des contraires. Sur Georges Bataille et le christianisme, Paris, Éditions du Sandre, 2010, pp. 175.

1 In questo saggio illuminante Per Buvik si pone l'obiettivo di ripercorrere il dialogo costante che Georges Bataille ha intrattenuto con il cristianesimo, nonostante l'aperta professione di ateismo, ciò che, d'altro canto, ha determinato l'atteggiamento spesso contraddittorio del celebre scrittore. Buvik dimostra, con ricchezza di informazioni e di argomentazioni, come il pensiero e l'opera di Bataille siano profondamente impregnati delle figure della tradizione cristiana, pur tenendo conto del fatto che Bataille era attratto esclusivamente dalla sua versione medievale, intrisa di misticismo e di senso del sacro, mentre rifiutava totalmente la dimensione dogmatica e moralistica del cattolicesimo.

Buvik si sofferma sul fervido dibattito che nel corso degli anni Quaranta scaturì tra Bataille e alcuni intellettuali cattolici, quali Jean Daniélou, Pierre Klossowski, Louis Massignon, Jean-Claude Renard, Gabriel Marcel, a cominciare dalla pubblicazione dell'Expérience intérieure (1943), per proseguire con la fertile discussione che si tenne il 5 marzo 1944 a casa dell'amico Marcel Moré, e che ebbe come protagonisti pensatori credenti e non credenti. Se gli intellettuali cattolici riconoscono la tensione mistica che anima Bataille che, come è noto, era un profondo ammiratore della mistica Angela da Foligno (1248-1309), tuttavia gli rimproverano, da un lato, di ragionare da intellettuale e non da mistico, dall'altro di rifiutare l'interezza del messaggio cristiano, con il suo portato di progettualità. La questione intorno alla quale si anima particolarmente il dibattito riguarda la concezione del sacrificio, che, oltre ad essere fondativo della religione cristiana a partire dalla crocefissione, occupa tanta parte nella riflessione di 
Bataille. Ma il filosofo, lungi dal considerare la dimensione salvifica insita nel sacrificio cristiano, esalta la valenza potentemente trasgressiva di un'esperienza che pone il soggetto, in tutta la sua corporeità ed umanità, al di là del limite, in un'ottica di pura dépense, come emerge anche dalla fotografia del suppliziato cinese Fou Tchou $\mathrm{Li}$ risalente al 1905, la quale aveva folgorato Bataille in gioventù, proprio per la sconvolgente «identité de ces parfaits contraires, opposant à l'extase divine une horreur extrême» (p. 93, cit. da Bataille, Les Larmes d'Éros, 1961). Proprio la cifra della trasgressione porta Bataille a considerare al pari del sacrificio cristiano e dell'estasi mistica anche il crimine e l'erotismo, tutte esperienze che trovano la propria ragion d'essere nel superamento di un limite, ovvero di un divieto, per ciò stesso situazioni che trascendono l'umano rendendolo divino. Come gli rimprovera Jean Daniélou, Bataille non ricerca nel cristianesimo un conforto, un approdo rassicurante, bensì l'incitazione alla trasgressione, ciò che lo induce a considerare il peccato come una componente ineludibile della religione. Ecco perché sia il santo che il peccatore vengono visti da Bataille come espressione del medesimo anelito verso un al di là del limite, la sovversione dell'ordine, come dimostra il binomio quanto mai inquietante di Giovanna d'Arco e di Gilles de Rais.

Alla luce dell'intenso dibattito che le posizioni di Bataille avevano suscitato tra $\mathrm{i}$ pensatori cattolici, a conferma della centralità dell'immaginario cristiano nella sua opera, Buvik attribuisce al saggio di Foucault Préface à la transgression (1963) una visione molto parziale, proprio per aver trascurato la tematica cristiana nel suo universo intellettuale (si veda, a questo proposito, la recente riedizione del testo: Michel Foucault, Préface à la transgression, Lignes, 2012). Come rammenta Francis Marmande nella postfazione, la Préface non prelude ad alcun testo a venire, trattandosi infatti di un saggio compiuto in sé, pubblicato su «Critique» nel 1963, nel numero doppio 195-196 dedicato a Bataille ad un anno dalla morte. Foucault vi tratta la tematica tipicamente batailliana della trasgressione legandola non solo alla preoccupazione del superamento del limite («La transgression est un geste qui concerne la limite», p. 16) ma anche all'immagine che ritorna nell'opera di Bataille dell'occhio, più concretamente l'occhio rovesciato dell'estasi e della morte, come allusione alla potenza dello sguardo che trasgredisce il confine che esso stesso delinea.

Ricordiamo che le edizioni Lignes hanno ripubblicato nel 2011, in un'unica edizione, i due testi di Bataille L'Anus solaire e Sacrifices, editi la prima volta rispettivamente nel 1931 e 1936. Pur trattandosi di due testi antecedenti la piena maturità filosofica dell'autore, essi contengono già in nuce le componenti essenziali della sua dialettica. L'Anus solaire si avvicina più a una prosa poetica che non filosofica, ricca di visioni telluriche che rimandano agli estremi dell'elevazione e della caduta, della verticalità e dell'orizzontalità, a cominciare dall'ossimoro contenuto nel titolo che associa alla solarità la funzione escrementizia della terra, attraverso l'immagine del vulcano. Sacrifices, di pochi anni posteriore, si configura già come una meditazione sul soggetto, colto nel momento della morte che trascende l'esistente, permettendogli così di accedere alla propria trascendenza sotto forma di io morente («Le moi n'accède à sa spécificité et à sa transcendance intégrale que sous la forme du "moi qui meurt"», p. 40). 